\title{
Mepanipyrim and cyprodinil induce divergent temporal patterns of AhR-mediated responses in zebrafish (Danio rerio) embryos and larvae
}

Chao Shen

Xiamen University

Chen Tang

Xiamen University

Kongyang Zhu

Xiamen University

Chengyong He

Xiamen University

Chunyan Yang

Xiamen University

Zhenghong Zuo ( $\sim$ zuozhenghong@xmu.edu.cn )

Xiamen University https://orcid.org/0000-0001-6705-3033

\section{Research Article}

Keywords: pesticides, Danio rerio, AhR agonists, cyp1a, EROD

Posted Date: October 26th, 2021

DOI: https://doi.org/10.21203/rs.3.rs-776853/v1

License: (1) This work is licensed under a Creative Commons Attribution 4.0 International License.

Read Full License 


\section{Abstract}

Mepanipyrim and cyprodinil are widely used to control and/or prevent fungal diseases in fruit culture. They are widely detected in aquatic environment and numerous food commodities including fruit and fruit products. Different from TCDD, mepanipyrim and cyprodinil are more easily degraded and metabolized in the environment. However, the in vivo analysis of their metabolic dynamics is unclear and need to be further confirmed. In this study, zebrafish embryos were constantly exposed to $100 \mu \mathrm{g} / \mathrm{L}$ mepanipyrim or cyprodinil for 7 days. The temporal pattern of CYP1A and AhR2 expression and EROD enzyme activity at different time frames during embryonic and larval development of zebrafish were investigated. Our results showed that mepanipyrim and cyprodinil tend to accumulate in zebrafish during early embryonic developmental stages. Meanwhile, mepanipyrim and cyprodinil exposure could increase the expression level of cyp $1 a$ and $a h r 2$ genes and EROD activity by a dynamic pattern in different developmental stages of zebrafish. Besides, their metabolites, which may accumulate in the zebrafish larvae, have strong AhR agonistic activity and showed strong AhR binding ability. Importantly, the risk of exposure to pesticides in embryo stage is huge, and should be paid more attention.

\section{Introduction}

Pesticides are proverbially used in agriculture to control insect pests for enhancing the yields and quality of crops (Sapbamrer \& Thammachai, 2020; Egbe et al., 2021). Globally, more than 1100 pesticides are marketed and developed for targeting specific pests in aquaculture, horticulture, agriculture and household (Meftaul et al., 2020; El-Nahhal, 2020). These pesticides include fungicides, herbicides, insecticides, rodenticides, etc. (Meftaul et al., 2020). Anilinopyrimidines are a chemical class of fungicides which can control and/or prevent fungal diseases in fruit culture (Castro et al., 2020). Mepanipyrim and cyprodinil belong to the anilinopyrimidine chemical family, and are widely used on the world-wide (Sieiro-Sampedro et al., 2019a; Chen et al., 2018; Tang et al., 2020). Their are broad-spectrum fungicides to target various phytopathogenic fungi by affecting the biosynthesis of hydrolases and methionine (Sieiro-Sampedro et al., 2019b; Shen et al., 2020). Due to their large usage, mepanipyrim and/or cyprodinil have been widely detected in aquatic environment, fruits and fruit products, and numerous food commodities (Esteve-Turrillas et al., 2015; Shen et al., 2020; Tang et al., 2020). For example, the residues of cyprodinil have been detected between $0.736-2.898 \mu \mathrm{g} / \mathrm{L}$ in the aquatic environment in Chile (Climent et al., 2019; Tang et al., 2020). Besides, cyprodinil residues have been detected between 41-907 $\mu \mathrm{g} / \mathrm{L}$ in commercial strawberry samples (Esteve-Turrillas et al., 2015). The residual levels of mepanipyrim in grapes and clarified wines are 2.0 and $0.2-0.7 \mathrm{mg} / \mathrm{L}$, respectively (BrizCid et al., 2019; Thais et al., 2019; Shen et al., 2020).

The aryl hydrocarbon receptor (AhR), a highly conserved ligand activated transcription factor, is one of the helix-loop-helix-containing transcription factors (Bugel et al., 2013; Eichbaum et al., 2014). It is vital for numerous hazardous chemicals to initiate many of their developmental toxicities and represents a crucial biomarker for risk assessment of organic contaminants (Bugiak et al., 2010; Meyer-Alert et al., 2019). It is well known that the AhR signaling pathway mediates cellular responses to extrinsic 
environmental contaminants, including benzo(a)pyrene (BaP), 2,3,7,8-tetrachlorodibenzo-p-dioxin (TCDD), polybrominated diphenyl ethers (PBDEs), etc. (Norman Haldén et al., 2011; Du et al., 2015; Wang et al., 2015). The inactive form of AhR is located in the cytoplasm and forms a complex with heat-shock-protein $90 \beta$ (HSP90ß) dimer, one molecular of AhR-interacting protein (AIP) and protein 23 (p23) (Meyer-Alert et al., 2018; Meyer-Alert et al., 2019). Upon ligand binding, the AhR dissociates from complex in the cytosol, and the nuclear localization signal of AhR is uncovered (Kudo et al., 2018; Meyer-Alert et al., 2018; Roy et al., 2020). Then the AhR immediately translocates into the nucleus and ultimately alters its co-factors with AhR-nuclear-translocator (ARNT) (Meyer-Alert et al., 2019). The AhR/ARNT heterodimer can bind to dioxin-responsed elements (DREs) and regulate the transcription of genes related to xenobiotic metabolism (Roy et al., 2019; Jin et al., 2020).

Dioxin-like compounds (DLCs) may induce cytochrome P450-dependent monooxygenases (CYPs) activity by binding to the AhR (Aguirre-Martínez et al., 2017). CYPs induction can reduce the danger of xenobiotic toxicity by accelerating the metabolism and excretion of xenobiotics to lower xenobiotic contents in the plasma or organisms (Loerracher \& Braunbeck, 2020). Cytochrome P450 1A (CYP1A) plays a crucial role in the detoxification and metabolism of organic pollutants (Zhao et al., 2017). For the determination of DLCs activity, ethoxyresorufin-O-deethylase (EROD) activity is usually regarded as a biomarker of AhRmediated induction of CYP1A, and is a highly sensitive indicator of dioxins and structurally related compounds (Whyte et al., 2000; Eichbaum et al., 2014; Kais et al., 2017; Kais et al., 2018). As a strong AhR ligand and the most toxic one of planar halogenated aromatic hydrocarbons (PHAHs), TCDD can continuously maintain the induced levels of CYP1A and EROD at a plateau for sustaining periods and is difficult to degrade and metabolize in vivo (Zodrow et al., 2004; Ortiz-Delgado et al., 2008; Chen \& Chan, 2018). This can lead to the accumulation of reactive oxygen species (ROS) in cells or organisms, and eventually result in oxidative damage of cell biomembrane, cell apoptosis, and death of the organisms (Lee \& Yang, 2010; Kalaiselvan et al., 2016; Liu et al., 2019). Previous studies have shown that mepanipyrim and cyprodinil as AhR agonists could induce the expression of AhR-regulated genes via AhR signaling pathway (Tang et al., 2020; Zhu et al., 2021). Different from TCDD, mepanipyrim and cyprodinil are more easily degraded and metabolized in the environment. However, the metabolic dynamics of them in vivo is unclear and need to be further confirmed.

Zebrafish (Danio rerio) has become a prevalent vertebrate model in several concernful lines of biological research, including environmental toxicology, drug discovery, disease models, developmental biology and neurobiology etc. (Carten et al., 2011; Zhang et al., 2016; Brugman, 2016; Kithcart \& MacRae, 2017; Anselmo et al., 2018; Shams et al., 2018). The embryos and larvae of zebrafish, as a valuable models in aquatic ecotoxicology, have gained increasing popularity to assess the effects of various pollutants (Velki et al., 2017; Shen \& Zuo, 2020). Besides, zebrafish screenings involving metabolite analysis at the different life stages of zebrafish are also common (Saad et al., 2017; Anselmo et al., 2018). This study was designed to analyze whether the activation of the detoxification metabolism through CYP1A could continuously be induced by mepanipyrim and cyprodinil exposure in zebrafish larvae and embryos. For this aim, we have detected the residues of mepanipyrim and cyprodinil in the embryos and larvae of zebrafish. At the same time, the temporal patterns of CYP1A and AhR2 expression and EROD enzyme 
activity at different time frames during embryonic and larval development of zebrafish were investigated $(24,48,72,96,120,144$, and 168 hours post fertilization (hpf)). In addition, we also predicted the AhR agonistic activity of several possible metabolites of mepanipyrim and cyprodinil by molecular docking method.

\section{Materials And Methods}

\subsection{Chemicals and reagents}

Mepanipyrim (CAS 110235-47-7; exceed 99\% purity) and cyprodinil (CAS 121552-61-2; 99.9\% purity) were acquired from Dr. Ehrenstorfer (Augsburg, Germany). TCDD (CAS 1746-01-6; $50 \mu \mathrm{g} / \mathrm{ml}$ ) was acquired from Wellington Laboratories, Inc. (Ontario, Canada). Dimethyl sulfoxide (DMSO; $99.7 \%$ purity) was acquired from Sigma-Aldrich (St. Louis, MO, USA). All other chemicals and reagents with analytical grade were acquired from mercantile origins.

\subsection{Zebrafish maintenance and embryonic exposure}

The wild-type TU zebrafish maintenance was based on our previous studies (Shen et al., 2020; Shen et al., 2021a). The mepanipyrim and cyprodinil were dispersed in DMSO to achieve stock solutions of $1 \mathrm{mg} / \mathrm{mL}$, respectively. TCDD (1 ng/L), mepanipyrim $(100 \mu \mathrm{g} / \mathrm{L})$, and cyprodinil $(100 \mu \mathrm{g} / \mathrm{L})$ exposure solutions were prepared by entering the proper volume of the stock solutions to the zebrafish culture medium. The control group was taken over a coordinative volume of DMSO solvent (0.01\%). Eighty embryos (0.5-1.0 hours post-fertilization (hpf)) were cultured in a glass dish containing $40 \mathrm{~mL}$ exposure solution $(\mathrm{n}=$ 5), which was renewed solutions once daily. The embryos were continuously exposed for $24,48,72,96$, 120,144 , and 168 hours to TCDD, mepanipyrim, or cyprodinil.

\subsection{Residue detection of mepanipyrim and cyprodinil}

The actual doses of mepanipyrim and cyprodinil in the exposure solutions were measured according to our previous study (Shen et al., 2020). In the residue detection of embryos and larvae, the embryos or larvae were homogenized in $0.2 \mathrm{~mL}$ acetonitrile, and then transferred to a $5 \mathrm{~mL}$ centrifuge tube with $1 \mathrm{~g}$ anhydrous sodium sulfate, $2 \mathrm{ml}$ acetonitrile, and $1 \mathrm{ml}$ acetonitrile-saturated $\mathrm{n}$-hexane. After centrifugation, the acetonitrile layer was extracted and dried with a nitrogen blowing instrument (EYELA MGS-2200, Japan). A solution of $0.1 \%$ formic acid-methanol: water (2: $8 \mathrm{v} / \mathrm{v})$ was used for volume determination. The separation was achieved on the chromatographic column (Kinetex 2.6u C18 100A $100 * 3.0 \mathrm{~mm}$ (Phenomenex, USA)), with a gradient elution using mobile phase consisted of ultrapure water (A) and $0.1 \%$ formic acid with acetonitrile (B) (S-Table 1 \& S-Table 2). The flow rate was 0.25 $\mathrm{mL} / \mathrm{min}$. The injection volume was $5 \mu \mathrm{L}$. A series of standard concentrations of mepanipyrim and cyprodinil $(0.5,2,10,50,100$, and 200 part per billion) were prepared to make the standard curve for 


\subsection{Real-time quantitative fluorescence PCR (RT-qPCR)}

Zebrafish embryos and larvae (6 samples/group, 25 embryos or larvae/sample) were mixed for RNA isolation. Total RNA extraction, cDNA synthesis, and RT-qPCR were carried out according to our previous studies (Zhou et al., 2019; Shen et al., 2020; Shen et al., 2021a). The primer sequences used for mRNA expression analysis of genes are listed in S-Table 3.

\subsection{Measurement of the EROD activity}

Zebrafish embryos and larvae (6 samples/group, 25 embryos or larvae/sample) were collected for EROD activity detection. A total volume of $75 \mu \mathrm{L}$ EROD buffer ( $3 \mu \mathrm{L}$ for per embryo or larva) was added to 1.5 $\mathrm{mL}$ reaction tube. Next, the samples were dispersed using a dispersing device (TIANGEN Biotech CO., LTD, Beijing) until completely dissociated. The homogenized samples were centrifuged at 3000 rotation per minute (rpm) and $4{ }^{\circ} \mathrm{C}$ for $15 \mathrm{~min}$. Total protein concentrations of the homogenized samples were analyzed using BCA Protein Assay Kit (EpiZyme, Shanghai, China). A resorufin (Sigma-Aldrich, Germany) standard was used for drawing the sample-specific standard curves. The supernatant of the homogenized samples were transferred to a white opaque 96-well plate to detect the EROD activity. In detail, 0.6 $\mu \mathrm{M}$ 7-ethoxyresorufin (Sigma-Aldrich, Germany) was added to each well, and was incubated in darkness at room temperature for $10 \mathrm{~min}$. Thereafter, $3.35 \mathrm{mM}$ NAPDH (Sigma-Aldrich, Germany) was added to each well, and was incubated in darkness at room temperature for $15 \mathrm{~min}$. Lastly, $1.35 \mathrm{mM}$ icecold acetonitrile-fluorescamine (Sigma-Aldrich, Germany) solution was added to stop the reaction. After 15 min, the fluorescence was measured by a POLARstar Omega automatic analysis system (BMG Labtech, Ortenberg, Germany) at $544 \mathrm{~nm}$ excitation and $590 \mathrm{~nm}$ emission. The EROD activity was calculated as $\mathrm{pmol}$ resorufin/min/mg protein.

\subsection{Molecular docking}

To examine the potential AhR activity of pesticides or their metabolites, AutoDock suite of programs was used to implement the molecular docking process. The ligand-binding domain sequence of AhR protein was obtained from UniProt (Entry ID: P35869). The detailed molecular docking process is based on our previous study (Tang et al., 2020; Zhu et al., 2021).

\subsection{Statistical analysis}

GraphPad Prism 7.0 (GraphPad Software, Inc., USA) was employed to carry out the statistical analysis of the data. The data (mean \pm standard errors, $n=3$ or 6 ) were analysed using the Duncan's post hoc test 
after one-way analysis of variance (ANOVA). ${ }^{\star \star \star} P<0.001 ;{ }^{* *} 0.001<P<0.01 ;{ }^{*} 0.01<P<0.05$; n.s. indicates no significant difference.

\section{Results}

\subsection{The residues of mepanipyrim and cyprodinil in zebrafish embryos and larvae}

The actual measured concentrations of mepanipyrim and cyprodinil in the exposure solutions were 65.60 \pm 11.71 and $62.75 \pm 4.94 \mu \mathrm{g} / \mathrm{L}$, respectively (Table 1 ). In order to better understand the metabolism of mepanipyrim and cyprodinil in the developmental process of zebrafish embryos and larvae, we detected the residues of mepanipyrim and cyprodinil in different developmental stages of zebrafish. The measured concentrations of mepanipyrim in 24 and $48 \mathrm{hpf}$ embryos of zebrafish were $5.16 \pm 0.16$ and $5.27 \pm 0.88$ $\mu \mathrm{g} / \mathrm{g}$, respectively (Fig. 1a, Table 2). However, with the development of embryos, mepanipyrim was gradually degraded and metabolized in larvae. The measured concentrations of mepanipyrim in 72,96 , 120,144 , and $168 \mathrm{hpf}$ larvae of zebrafish were $1.83 \pm 0.20,0.98 \pm 0.30,0.15 \pm 0.01,0.06 \pm 0.02$, and 0.08 $\pm 0.01 \mu \mathrm{g} / \mathrm{g}$, respectively (Fig. 1a, Table 2). Compared with mepanipyrim, cyprodinil was easier to accumulate in zebrafish larvae. The measured concentrations of cyprodinil in 24,48 , and $72 \mathrm{hpf}$ embryos or larvae of zebrafish were $18.71 \pm 1.94,19.56 \pm 2.32$, and $18.41 \pm 0.83 \mu \mathrm{g} / \mathrm{g}$, respectively (Fig. $1 \mathrm{~b}$, Table 2). However, cyprodinil was also gradually degraded and metabolized in larvae after 72 hours. The measured concentrations of cyprodinil in $96,120,144$, and 168 hpf larvae of zebrafish were $2.40 \pm 0.13$, $0.15 \pm 0.02,0.36 \pm 0.06$, and $0.53 \pm 0.07 \mu \mathrm{g} / \mathrm{g}$, respectively (Fig. $1 \mathrm{~b}$, Table 2).

Table 1

Mean measured concentrations of mepanipyrim \& cyprodinil $(\mu \mathrm{g} / \mathrm{L} \pm \mathrm{SD}$ ) in the water samples $(n=3)$.

\begin{tabular}{|lll|}
\hline $\begin{array}{l}\text { Nominal concentration } \\
(\mu \mathrm{g} / \mathrm{L})\end{array}$ & $\begin{array}{l}\text { Measured concentration } \\
\text { (mepanipyrim, } \mu \mathrm{g} / \mathrm{L})\end{array}$ & $\begin{array}{l}\text { Measured concentration } \\
\text { (cyprodinil, } \mu \mathrm{g} / \mathrm{L} \text { ) }\end{array}$ \\
\hline 0 & $0.11 \pm 0.01$ & $0.16 \pm 0.04$ \\
\hline 100 & $65.60 \pm 11.71$ & $62.75 \pm 4.94$ \\
\hline
\end{tabular}


Table 2

Mean measured concentrations of mepanipyrim \& cyprodinil $(\mu \mathrm{g} / \mathrm{g} \pm \mathrm{SD})$ in zebrafish larvae or embryos $(n=3)$.

\begin{tabular}{|llllllll|}
\hline $\begin{array}{l}\text { Nominal } \\
\text { concentration }(\mu \mathrm{g} / \mathrm{L})\end{array}$ & \multicolumn{6}{l|}{ Larvae exposed days (D), measured concentration $(\mu \mathrm{g} / \mathrm{g})$} \\
\cline { 2 - 8 } & 1 D & 2 D & 3 D & 4 D & 5 D & 6 D & 7 D \\
\hline Mepanipyrim-100 & $5.16 \pm$ & $5.27 \pm$ & $1.83 \pm$ & $0.98 \pm$ & $0.15 \pm$ & $0.06 \pm$ & $0.08 \pm$ \\
& 0.16 & 0.88 & 0.20 & 0.30 & 0.01 & 0.02 & 0.01 \\
\hline Cyprodinil-100 & $18.71 \pm$ & $19.56 \pm$ & $18.41 \pm$ & $2.40 \pm$ & $0.15 \pm$ & $0.36 \pm$ & $0.53 \pm$ \\
& 1.94 & 2.32 & 0.83 & 0.13 & 0.02 & 0.06 & 0.07 \\
\hline D: days. & & & & & & & \\
\hline
\end{tabular}

\subsection{The mRNA expression of cyp1a and ahr2 genes in mepanipyrim or cyprodinil exposed embryos and larvae}

We next examined the temporal pattern of cyp1a and ahr2 mRNA expression during zebrafish early developmental process. The mRNA expression patterns of cyp1a gene after exposure to mepanipyrim or cyprodinil show differences compared with TCDD exposure. Expression of cyp1a gene in embryos and larvae was dynamically induced by mepanipyrim and cyprodinil (Fig. 2a). However, the expression of cyp 1a in embryos and larvae was continuously induced by TCDD. The number of cyp1a transcripts was constantly increased by TCDD exposure and reached about 2000-fold change in $7 \mathrm{dpf}$ larvae compared with $24 \mathrm{hpf}$ solvent control embryos (Fig. 2a). At the same time, the mRNA expression of ahr2 gene was also showed a dynamic induction by mepanipyrim and cyprodinil exposure (Fig. 2b). Nevertheless, the mRNA expression of ahr2 gene was showed a continuous induction by TCDD exposure (Fig. 2b).

\subsection{The EROD activities of mepanipyrim or cyprodinil exposed embryos and larvae}

EROD activity is usually regarded as a biomarker of AhR-mediated induction of CYP1A, and is a highly sensitive indicator of dioxins and structurally related compounds (Whyte et al., 2000; Eichbaum et al., 2014; Kais et al., 2017; Kais et al., 2018). To further confirm our results, we detected the EROD activity of mepanipyrim and cyprodinil exposed embryos and larvae. As shown in Fig. 3, the EROD activities of embryos and larvae were dynamically altered by mepanipyrim and cyprodinil exposure, while TCDD exposure lead strong increase in EROD activities.

\subsection{The AhR agonistic activities of mepanipyrim and cyprodinil metabolites}

To detect the AhR agonistic activity of potential metabolites of mepanipyrim and cyprodinil, molecular docking method was used to explore the binding energies between their metabolites and AhR. The 
smaller binding energies indicating better interaction activity. As shown in Table 3, the binding energy of strong AhR agonist TCDD interacting with AhR was $-8.5 \mathrm{kcal} / \mathrm{mol}$, and the binding energy of mepanipyrim and cyprodinil interacting with AhR were -9.3 and $-9.5 \mathrm{kcal} / \mathrm{mol}$, respectively. In addition, the binding energy of two potential metabolites (No. 5 and No. 10) of cyprodinil interacting with AhR were -9.2 and $-6.6 \mathrm{kcal} / \mathrm{mol}$, respectively. And the binding energy of five potential metabolites (No. 4, No. 6, No. 7 , No. 8, and No. 9) of mepanipyrim interacting with AhR were $-8.3,-8.9,-8.9,-6.8$, and $-8.7 \mathrm{kcal} / \mathrm{mol}$, respectively.

\section{Discussion}

Developing fish are one of the most sensitive organisms to TCDD and other DLCs (Teraoka et al., 2003). The CYPs play a crucial role in the metabolism and degradation of hazardous compounds (Guengerich, 2017; Loerracher et al., 2020). Among the CYPs, cyp1a is the best characterized and is the strongest response in TCDD bio-activation in fish (Chuang et al., 2004; Jonsson et al., 2009; Chen \& Chan, 2018). As a persistent organic pollutant, TCDD is very difficult to be degraded and metabolized in organisms (Sorg et al., 2009; Sorg, 2014). Due to its persistent existence in organisms, it can constantly induce the expression of AhR targeting gene cyp1a (Roy et al., 2011; Hervé et al., 2010; Bock, 2018; Roy et al., 2018). CYP1A protein is first detected at $36 \mathrm{hpf}$ zebrafish larvae after exposure to TCDD, and constitutive expression of CYP1A is demonstrated in the $120 \mathrm{hpf}$ larval zebrafish (Andreasen et al., 2002; Otte et al., 2010). Many studies have shown that low concentration of TCDD could strongly induce the expression of cyp1a in many tissues of zebrafish, especially in the liver and gut (Kim et al., 2013; Shen et al., 2018; Xie et al., 2018). Similarly, we found that $1 \mathrm{ng} / \mathrm{L}$ TCDD exposure could dramatically induce the expression of cyp1a by a constant increasing pattern in zebrafish larvae. These results further indicate the persistence of TCDD in organisms.

CYP1A is commonly associated with the biotransformation of environmental contaminants, especially the DLCs (Cardoso et al., 2019; Licata et al., 2019). Many DLCs including pesticides belong to the substrates of CYP1A enzyme biotransformation, which are usually converted to more hydrophilic metabolites for excretion (Roy et al., 2019). Besides, CYP1A induction can also produce toxic effects by promoting the production of active metabolites (Voelker et al., 2008). We found that mepanipyrim and cyprodinil exposure could induce the expression of cyp1a by a dynamic pattern in different developmental stages of zebrafish. Meanwhile, the potential metabolites of mepanipyrim and cyprodinil also have AhR agonistic activity, indicating the induction of cyp1a expression could also be mediated by their metabolites.

As a target gene of AhR, the change of cyp1a expression is closely related to the successful entry of AhR into nucleus and the formation of AhR/ARNT dimer acting on dioxin-responsive elements (Denison et al., 2017; Vogel et al., 2020). AhR located in the cytoplasm remains inactive before binding ligands (Reynaud \& Deschaux, 2006; AnvariFar et al., 2018). The storage of AhR in the cytoplasm always maintains a dynamic balance (Bell \& Poland, 2000; Mejía-García, et al., 2015). It can play a nuclear receptor role only after ligand binding or activation by phosphorylation (Guyot et al., 2013). Many studies have reported 
that DLCs can strongly induce the expression of ahr2 (Guo et al., 2017; Zhou et al., 2020). The increased mRNA expression of ahr2 have become an important toxic indicator of DLCs (Cheng et al., 2020). In the present study, we found that the mRNA expression of ahr2 also showed a dynamic change by mepanipyrim or cyprodinil exposure, and was consistent with the expression of cyp1a in zebrafish. The continuous activation of AhR signaling pathway is a crucial condition to ensure that mepanipyrim and cyprodinil can be effectively degraded and metabolized (Hale et al., 2017).

Over-expression of CYP1A is involved in production of reactive oxygen species (ROS) (Zangar et al., 2004). Previous study found that TCDD could induce ROS production by up-regulating the expression of CYP1A, which could further cause damage to DNA (Kopf \& Walker, 2010; Kalaiselvan et al., 2016; Liu et al., 2019). Besides, pesticides exposure can result in the transformation of toxic substances into ROS, which can ultimately cause cell injury (Singh et al., 2018; Shen et al., 2021b). In the present study, we found that the mRNA expression of cyp1a in zebrafish larvae was significantly increased by mepanipyrim or cyprodinil exposure, indicating that mepanipyrim and cyprodinil may increase the level of ROS. Under normal physiological conditions, the production of ROS can promote the growth and development of cells or organisms. However, excessive production of ROS can cause great damage to cell components, such as biomembrane and cell membrane, which will seriously affect the "dynamic balance" of cells or organisms (Suzuki et al., 2012; Bhagat et al., 2020).

Because of the short half-life, the pesticides exhibit a short term toxic effects after application and/or exposure (Korkmaz et al., 2018). During pregnancy, pesticides have the potential to pass through the placental barrier and disturb the fetal development (Dewailly et al., 2014). In addition, pesticides are likely to accumulate in the organisms in early embryonic developmental stages (Gavelle et al., 2016; Kuang et al., 2020). Our results showed that mepanipyrim and cyprodinil tended to accumulate in zebrafish during early developmental stages. With the development of zebrafish, mepanipyrim and cyprodinil began to be degraded and metabolized. These results implied that organisms were sensitive to pesticides in early life, and pesticides were more likely to accumulate in early life stages of organisms. At the same time, pesticides exposure in early life may affect the normal development of organisms. Therefore, the risk of exposure to pesticides in embryo stage is huge, and should be paid more attention. Furthermore, pregnant women, in particular, should avoid to be exposed to pesticides, such as the diets with pesticide residues during pregnancy (Dewailly et al., 2014).

The induction of EROD activity is often used to assess the AhR agonistic activity of dioxins and DLCs in organisms (Eichbaum et al., 2014; Kais et al., 2017; Ji et al., 2021). TCDD can dramatically increase the EROD activity in the liver, kidney, and gills of seabream, Sparus aurata (Ortiz-Delgado et al., 2008). Basal EROD enzymatic activity is detected in $6 \mathrm{hpf}$ zebrafish embryos, after then, it has constantly increased by a slow pattern (Meyer-Alert et al., 2018; Meyer-Alert et al., 2019). Previously, Xu et al. (2018) found that TCDD exposure could cause prominent elevation of EROD activity in larval zebrafish. In the present study, our results showed that $1 \mathrm{ng} / \mathrm{L}$ TCDD exposure could dramatically increase the EROD activity in different development stages of zebrafish. It was consistent with the increase of cyp1a mRNA expression induced by TCDD. At the same time, we found that mepanipyrim and cyprodinil exposure could increase the EROD 
activity with a dynamic pattern in different developmental stages of zebrafish. It also implied that the potential metabolites of mepanipyrim and cyprodinil could increase the EROD activity in zebrafish larvae.

Unlike persistent organic pollutants, pesticides are easier to be degraded and metabolized (Velki et al., 2017). But their metabolites may be difficult to be degraded and could accumulate in the organism for a long time. Our study found that embryonic exposure to diuron for 7 days, diuron could quickly be degraded into its two major metabolites $N$-demethyldiuron (DCPMU) and $N$-didemethyldiuron (DCPM) in zebrafish larvae. Meanwhile, DCPMU and DCPU could gradually accumulate in the larvae with the extension of exposure time (unpublished data). In the present study, we found that mepanipyrim and cyprodinil could also be quickly degraded, and their residues in larvae decreased with the exposure time. Therefore, we speculated that their potential metabolites may accumulate in the zebrafish larvae. Previously, it has been reported that mepanipyrim and cyprodinil exhibit a very strong AhR agonistic activity and can dramatically induce the expression of AhR-regulated genes (Tang et al., 2020; Zhu et al., 2021). Presently, we found that mepanipyrim or cyprodinil had strong binding with AhR, even stronger than TCDD. Besides, their metabolites also had strong AhR agonistic activity and showed strong AhR binding ability. The residues of mepanipyrim or cyprodinil in $5 \mathrm{dpf}$ zebrafish larvae were very low, but the cyp1a expression and EROD activity did not return to normal level, indicating that their metabolites could accumulate in larvae. This is very consistent with our hypothesis. Unfortunately, there are no commercial metabolites available in the market, so it is impossible to carry out substantive verification. To sum up, a direct temporal relation between CYP1A or EROD induction and mepanipyrim or cyprodinil exposure is still vaguely indicated by the present results and further research is required.

\section{Conclusion}

This study was designed to analyze whether the activation of the detoxification metabolism through CYP1A could be continuously induced by mepanipyrim and cyprodinil exposure in zebrafish larvae and embryos. Our results showed that mepanipyrim and cyprodinil tended to accumulate in zebrafish during early embryonic developmental stages. With the development of embryos, mepanipyrim and cyprodinil were gradually degraded and metabolized in larvae. Meanwhile, mepanipyrim and cyprodinil exposure could increase the expression of cyp1a and ahr2 genes and EROD activity by a dynamic pattern in different developmental stages of zebrafish. Besides, their metabolites, which may accumulate in the zebrafish larvae, have strong AhR agonistic activity and showed strong AhR binding ability.

\section{Declarations}

\section{Funding}

This work was supported by the National Natural Science Foundation of China (No. 31971234) and the Natural Science Foundation of Fujian Province of China (No. 2018J01067).

\section{Conflicts of interest statement}


The authors declare that they have no conflict of interest.

\section{Author contributions}

Chao Shen: Conceptualization, Methodology, Investigation, Writing-Original draft preparation, WritingReviewing and Editing; Chen Tang: Methodology, Investigation; Kongyang Zhu: Methodology, Investigation; Chengyong He: Project administration, Supervision, Validation, Writing-Reviewing and Editing; Chunyan Yang: Supervision, Validation, Writing-Reviewing and Editing; Zhenghong Zuo: Funding acquisition, Project administration, Resources, Visualization, Writing-Reviewing and Editing.

\section{Ethics approval}

All experiments using zebrafish were performed according to the animal protocol approved by the guides of Animal Ethics Committee of Xiamen University.

\section{Consent to participate and consent for publication}

Not applicable.

\section{Availability of data and materials}

The obtained and analyzed data of this study are available from the corresponding author on reasonable request.

\section{References}

1. Aguirre-Martínez GV, Reinardy HC, Laura Martín-Díaz M, Henry TB (2017) Response of gene expression in zebrafish exposed to pharmaceutical mixtures: Implications for environmental risk. Ecotox Environ Safe 142:471-479

2. Andreasen EA, Spitsbergen JM, Tanguay RL, Stegeman JJ, Heideman W, Peterson RE (2002) Tissuespecific expression of AHR2. ARNT2, and CYP1A in zebrafish embryos and larvae: Effects of developmental stage and 2,3,7,8-tetrachlorodibenzo-p-dioxin exposure. Toxicol Sci 68:403-419

3. Anselmo CS, Sardela VF, Sousa VP, Pereira HMG (2018) Zebrafish (Danio rerio): A valuable tool for predicting the metabolism of xenobiotics in humans? Comp Biochem Physiol C - Toxicol Pharmacol 212:34-46

4. AnvariFar H, Amirkolaie AK, Jalali AM, Miandare HK, Sayed AH, Üçüncü SI, Ouraji H, Ceci M, Romano N (2018) Environmental pollution and toxic substances: Cellular apoptosis as a key parameter in a sensible model like fish. Aquat Toxicol 204:144-159

5. Bell DR, Poland A (2000) Binding of aryl hydrocarbon receptor (AhR) to AhR-interacting protein: The role of hsp90. J Biol Chem 275(46):36407-36414

6. Bhagat J, Zang LQ, Nishimura N, Shimada Y (2020) Zebrafish: An emerging model to study microplastic and nanoplastic toxicity. Sci Total Environ 728:138707 
7. Bock KW (2018) From TCDD-mediated toxicity to searches of physiologic AhR functions. Biochem Pharmacol 155:419-424

8. Briz-Cid N, Rial-Otero R, Cámara MA, Oliva J, Simal-Gandara J (2019) Dissipation of three fungicides and their effects on anthocyanins and color of monastrell red wines. Int J Mol Sci 20:1447

9. Brugman S (2016) The zebrafish as a model to study intestinal inflammation. Dev Comp. Immunol. 64:82-92

10. Bugel SM, White LA, Cooper KR (2013) Inhibition of vitellogenin gene induction by 2,3,7,8tetrachlorodibenzo-p-dioxin is mediated by aryl hydrocarbon receptor 2 (AHR2) in zebrafish (Danio rerio). Aquat Toxicol 126:1-8

11. Bugiak BJ, Weber LP (2010) Phenotypic anchoring of gene expression after developmental exposure to aryl hydrocarbon receptor ligands in zebrafish. Aquat Toxicol 99(3):423-437

12. Cardoso PG, Resende de Oliveira R, Rocha E (2019) Combined effects of increased temperature and levonorgestrel exposure on zebrafish female liver, using stereology and immunohistochemistry againist catalase, CYP1A, HSP90 and vitellogenin. Environ Pollut 252:1059-1067

13. Carten JD, Bradford MK, Farber SA (2011) Visualizing digestive organ morphology and function using differential fatty acid metabolism in live zebrafish. Dev Biol 360:276-285

14. Castro G, Pérez-Mayán L, Carpinteiro I, Ramil M, Cela R, Rodríguez I (2020) Residues of anilinopyrimidine fungicides and suspected metabolites in wine samples. J Chromatogr $A$ 1622:461104

15. Chen XX, He S, Liu XL, Hu JY (2018) Biobegradation and metabolic mechanism of cyprodinil by strain Acinetobacter sp. From a contaminated-agricultural soil in China. Ecotox Environ Safe 159:190-197

16. Chen YY, Chan KM (2018) Modulations of TCDD-mediated induction of zebrafish cyp1a1 and the AHR pathway by administering $\mathrm{Cd}^{2+}$ in vivo. Chemosphere 210:577-587

17. Cheng ZH, Huo X, Dai YF, Lu XL, Hylkema MN, Xu XJ (2020) Elevated expression of AhR and NLRP3 link polycyclic aromatic hydrocarbon exposure to cytokine storm in preschool children. Environ Int 139:105720

18. Chung WG, Sen A, Wang-Buhler JL, Yang YH, Lopez N, Merrill GF, Miranda CL, Hu CH, Buhler DR (2004) cDNA-directed expression of a functional zebrafish CYP1A in yeast. Aquat Toxicol 70(2):111121

19. Climent MJ, Herrero-Hernandez E, Sanchez-Martin MJ, Rodriguez-Cruz MS, Pedreros P, Urrutia R (2019) Residues of pesticides and some metabolites in dissolved and particulate phase in surface stream water of Cachapoal River basin, central Chile. Environ Pollut 251:90-101

20. Denison MS, Faber SC (2017) And now for something completely different: Diversity in liganddependent activation of Ah receptor response. Curr Opin Toxicol 2:124-131

21. Dewailly E, Forde M, Robertson L, Kaddar N, Sidi L, Côté EA, Gaudreau S, Drescher E, Ayotte O, P (2014) Evaluation of pyrethroid exposures in pregnant women from 10 Caribbean countries. Environ 
Int 63:201-206

22. Du MM, Fang C, Qiu L, Dong SJ, Zhang X, Yan CZ (2015) Diastereoisomer-specific effects of hexabromocyclododecanes on hepatic aryl hydrocarbon receptors and cytochrome P450s in zebrafish (Danio rerio). Chemosphere 132, 24-31

23. Egbe CC, Oyetibo GO, Ilori MO (2021) Ecological impact of organochlorine pesticides consortium on autochthonous microbial community in agricultural soil. Ecotox Environ Safe 207:111319

24. Eichbaum K, Brinkmann M, Buchinger S, Reifferscheid G, Hecker M, Giesy JP, Engwall M, van Bavel B, Hollert H (2014) In vitro bioassays for detecting dioxin-like activity: Application potentials and limits of detection, a review. Sci Total Environ 487:37-48

25. El-Nahhal Y (2020) Pesticide residues in honey and their potential reproductive toxicity. Sci Total Environ 741:139953

26. Esteve-Turrillas FA, Abad-Somovilla A, Quiñones-Reyes G, Agulló C, Mercader JV, Abad-Fuentes A (2015) Monoclonal antibody-based immunoassays for cyprodinil residue analysis in QuEChERSbased fruit extracts. Food Chem 187:530-536

27. Gavelle E, Lauzon-Guillain B, Charles MA, Chevrier C, Hulin M, Sirot V, Merlo M, Nougadère A (2016) Chronic dietary exposure to pesticide residues and associated risk in the French ELFE cohort of pregnant women. Environ Int 92-93:533-542

28. Guengerich FP (2017) Intersection of the roles of cytochrome P450 enzymes with xenobiotic and endogenous substrates: relevance to toxicity and drug interactions. Chem Res Toxicol 30(1):2-12

29. Guo R, Pan L, Lin P, Zheng L (2017) The detoxification responses, damage effects and bioaccumulation in the scallop Chlamys farreri exposed to single and mixtures of benzo[a]pyrene and chrysene. Comp Biochem Physiol C Toxicol Pharmacol 191:36-51

30. Guyot E, Chevallier A, Barouki R, Coumoul X (2013) The AhR twist: ligand-dependent AhR signaling and pharmaco-toxicological implications. Drug Discov Today 18(9-10):479-486

31. Hale MD, Galligan TM, Rainwater TR, Moore BC, Wilkinson PM, Guillette LJ, Parrott BB, 2017. AHR and CYP1A expression link historical contamination events to modern day developmental effects in the American alligator. Environ. Pollut. 230, 1050-1061

32. Hervé JC, Crump D, Giesy JP, Zwiernik MJ, Bursian SJ, Kennedy SW (2010) Ethoxyresorufin Odeethylase induction by TCDD, PeCDF and TCDF in ring-necked pheasant and Japanese quail hepatocytes: Time-dependent effects on concentration-response curves. Toxicol Vitro 24(4):13011305

33. Ji CY, Chen D, Zhao MR (2021) Environmental behavior and safety of polyhalogenated carbazoles (PHCZs): A review. Environ Pollut 268:115717

34. Jin HM, Ji C, Ren F, Aniagu S, Tong J, Jiang Y, Chen T (2020) AHR-mediated oxidative stress contributes to the cardiac developmental toxicity of trichloroethylene in zebrafish embryos. J Hazard Mater 385:121521

35. Jonsson ME, Brunstrom B, Brandt I (2009) The zebrafish gill model: induction of CYP1A, EROD and PAH adduct formation. Aquat Toxicol 91(1):62-70 
36. Kais B, Ottermanns R, Scheller F, Braunbeck T (2018) Modification and quantification of in vivo EROD live-imaging with zebrafish (Danio rerio) embryos to detect both induction and inhibition of CYP1A. Sci Total Environ 615:330-347

37. Kais B, Schiwy S, Hollert H, Keiter SH, Braunbeck T (2017) In vivo EROD assays with the zebrafish (Danio rerio) as a rapid screening tools for the detection of dioxin-like activity. Sci Total Environ 590591:269-280

38. Kalaiselvan I, Senthamarai M, Kasi PD (2016) 2,3,7,8-TCDD-mediated toxicity in peripheral blood mononuclear cells is alleviated by the antioxidants present in Gelidiella acerosa: an in vitro study. Environ Sci Pollut Res 23:5111-5121

39. Kim KH, Park HJ, Kim JH, Kim S, Williams DR, Kim MK, Jung YD, Teraoka H, Park HC, Choy HE, Shin BA, Choi SY (2013) Cyp1a reporter zebrafish reveals target tissues for dioxin. Aquat. Toxicol. 134$135,57-65$

40. Kithcart A, MacRae CA (2017) Using zebrafish for high-throughput screening of novel cardiovascular drugs. JACC Basic Transl Sci 2:1-12

41. Kopf PG, Walker MK (2010) 2,3,7,8-Tetrachlorodibenzo-p-dioxin increases reactive oxygen species production in human endothelial cells via induction of cytochrome P4501A1. Toxicol Appl Pharmacol 245:91-99

42. Korkmaz V, Güngördü A, Ozmen M (2018) Comparative evaluation of toxicological effects and recovery patterns in zebrafish (Danio rerio) after exposure to phosalone-based and cypermethrinbased pesticides. Ecotox Environ Safe 160:265-272

43. Kuang LH, Hou YZ, Huang FQ, Hong HC, Sun HJ, Deng WJ, Lin HJ (2020) Pesticide residues in breast milk and the associated risk assessment: A review focused on China. Sci Total Environ 727:138412

44. Kudo I, Hosaka M, Haga A, Tsuji N, Nagata Y, Okada H, Fukuda K, Kakizaki Y, Okamoto T, Grave E, Itoh $\mathrm{H}$ (2018) The regulation mechanisms of AhR by molecular chaperone complex. J Biochem 163(3):223-232

45. Lee HG, Yang JH (2010) PKC- $\delta$ mediates TCDD-induced apoptosis of chondrocyte in ROS-dependent manner. Chemosphere 81(8):1039-1044

46. Licata P, Piccione G, Fazio F, Laurino ER, Calò M (2019) Protective effects of genistein on cytochrome P-450 and vitellogenin expression in liver of zebrafish after PCB-126 exposure. Sci Total Environ 674:71-76

47. Liu HL, Shi LH, Giesy JP, Yu HX (2019) Polychlorinated diphenyl sulfides can induce ROS and genotoxicity via the AhR-CYP1A1 pathway. Chemosphere 223:165-170

48. Loerracher AK, Braunbeck T (2020) Inducibility of cytochrome P450-mediated 7-methoxycoumarin-Odemethylase activity in zebrafish (Danio rerio) embryos. Aquat Toxicol 225:105540

49. Loerracher AK, Grethlein M, Braunbeck T (2020) In vivo fluorescence-based characterization of cytochrome P450 activity during embryonic development of zebrafish (Danio rerio). Ecotox Environ Safe 192:110330 
50. Meftaul IM, Venkateswarlu K, Dharmarajan R, Annamalai P, Megharaj M (2020) Pesticides in the urban environment: A potential threat that knocks at the door. Sci Total Environ 711:134612

51. Mejía-García A, González-Barbosa E, Martínez-Guzmán C, Torres-Ramos MA, Rodríguez MS, GuzmánLeón S, Elizondo G (2015) Activation of AhR mediates the ubiquitination and proteasome degradation of c-Fos through the induction of $U b c m 4$ gene expression. Toxicology 337:47-57

52. Meyer-Alert H, Ladermann K, Larsson M, Schiwy S, Hollert H, Keiter SH (2018) A temporal highresolution investigation of the Ah-receptor pathway during early development of zebrafish (Danio rerio). Aquat Toxicol 204:117-129

53. Meyer-Alert H, Larsson M, Hollert H, Keiter SH (2019) Benzo[a]pyrene and 2,3-benzofuran induce divergent temporal patterns of AhR-regulated response in zebrafish embryos (Danio rerio). Ecotox Environ Safe 183:109505

54. Norman Haldén A, Arnoldsson K, Haglund P, Mattsson A, Ullerås E, Sturve J, Norrgren L (2011) Retention and maternal transfer of brominated dioxins in zebrafish (Danio rerio) and effects on reproduction, aryl hydrocarbon receptor-regulated genes, and ethoxyresorufin- $O$-deethylase (EROD) activity. Aquat Toxicol 102(3-4):150-161

55. Ortiz-Delgado JB, Behrens A, Segner H, Sarasquete C (2008) Tissue-specific induction of EROD activity and CYP1A protein in Sparus aurata exposed to B(a)P and TCDD. Ecotox Environ Safe 69(1):80-88

56. Otte JC, Schmidt AD, Hollert H, Braunbeck T (2010) Spatio-temporal development of CYP1 activity in early life-stages of zebrafish (Danio rerio). Aquat Toxicol 100(1):38-50

57. Reynaud S, Deschaux P (2006) The effects of polycyclic aromatic hydrocarbons on the immune system of fish: A review. Aquat Toxicol 77(2):229-238

58. Roy MA, Duche PR, Timme-Laragy AR (2020) The sulfate metabolite of 3,3'-dichlorobiphenyl (PCB11) impairs Cyp1a activity and increases hepatic neutral lipids in zebrafish larvae (Danio rerio). Chemosphere 260:127609

59. Roy MA, Sant KE, Venezia OL, Shipman AB, McCormick SD, Saktrakulkla P, Hornbuckle KC, TimmeLaragy AR (2019) The emerging contaminant 3,3'-dichlorobiphenyl (PCB-11) impedes Ahr activation and Cyp1a activity to modify embryotoxicity of Ahr ligands in the zebrafish embryo model (Danio rerio). Environ Pollut 254:113027

60. Roy NK, Candelmo A, DellaTorre M, Chambers C, Nádas R, Wirgin A, I (2018) Characterization of AhR2 and CYP1A expression in Atlantic sturgeon and shortnose sturgeon. Aquat Toxicol 197:19-31

61. Roy NK, Walker N, Chambers C, Wirgin R, I (2011) Characterization and expression of cytochrome P4501A in Atlantic sturgeon and shortnose sturgeon experimentally exposed to coplanar PCB126 and TCDD. Aquat Toxicol 104(1-2):23-31

62. Saad M, Matheeussen A, Bijttebier S, Verbueken E, Pype C, Casteleyn C, Van Ginneken C, Apers S, Maes L, Cos P, Van Cruchten S (2017) In vitro CYP-mediated drug metabolism in the zebrafish (embryo) using human reference compounds. Toxicol In Vitro 42:329-336 
63. Sapbamrer R, Thammachai A (2020) Factors affecting use of personal protective equipment and pesticide safety practices: A systematic review. Environ Res 185:109444

64. Shams S, Rihel J, Ortiz JG, Gerlai R (2018) The zebrafish as a promising tool for modeling human brain disorders: A review based upon an IBNS Symposium. Neurosci. Biobehav. Rev. 85, 176-190

65. Shen C, Zhou YX, Ruan JP, Chuang YJ, Wang CG, Zuo ZH (2018) Generations of a Tg(cyp1a12DRE:EGFP) transgenic zebrafish line as a rapid in vivo model for detecting dioxin-like compounds. Aquat Toxicol 205:174-181

66. Shen C, Zhou YX, Tang C, He CY, Zuo ZH (2020) Developmental exposure to mepanipyrim induces locomotor hyperactivity in zebrafish (Danio rerio) larvae. Chemosphere 256:127106

67. Shen C, Zhu KY, Ruan JP, Li JL, Wang Y, Zhao MR, He CY, Zuo ZH (2021a) Screening of potential oestrogen receptor a agonists in pesticides via in silico, in vitro and in vivo methods. Environ. Pollut. 270, 116015

68. Shen C, Zuo ZH (2020) Zebrafish (Danio rerio) as an excellent vertebrate model for the development, reproductive, cardiovascular, and neural and ocular development toxicity study of hazardous chemicals. Environ Sci Pollut Res 27:43599-43614

69. Shen J, Liu P, Sun YQ, Xu XX, Guo LF, Rao Q, Chen ML, Liu XY (2021b) Embryonic exposure to prothioconazole induces oxidative stress and apoptosis in zebrafish (Danio rerio) early life stage. Sci Total Environ 756:143859

70. Sieiro-Sampedro T, Pose-Juan E, Briz-Cid N, Figueiredo-González M, Torrado-Agrasar A, GonzálezBarreiro C, Simal-Gandara J, Cancho-Grande B, Rial-Otero R (2019a) Mepanipyrim residues on pasteurized red must influence the volatile derived compounds from Saccharomyces cerevisiae metabolism. Food Res Int 126:108566

71. Sieiro-Sampedro T, Figueiredo-González M, González-Barreiro C, Simal-Gandara J, Cancho-Grande B, Rial-Otero R (2019b) Impact of mepanipyrim and tetraconazole in Mencía wines on the biosynthesis of volatile compounds during the winemaking process. Food Chem 300:125223

72. Singh N, Lawana V, Luo J, Phong P, Abdalla A, Palanisamy B, Rokad D, Sarkar S, Jin H, Anantharam V, Kanthasamy AG, Kanthasamy A (2018) Oganophosphate pesticide chlorpyrifos impairs STAT1 signaling to induce dopaminergic neurotoxicity: implications for mitochondria mediated oxidative stress signaling events. Neurobiol Dis 117:82-113

73. Sorg $O$ (2014) AhR signaling and dioxin toxicity. Toxicol Lett 230(2):225-233

74. Sorg O, Zennegg M, Schmid P, Fedosyuk R, Valikhnovskyi R, Gaide O, Kniazevych V, Saurat JH (2009) 3,7,8-tetrachlorodibenzo-p-dioxin (TCDD) poisoning in Victor Yushchenko: identification and measurement of TCDD metabolites. Lancet 374 2:1179-1185

75. Suzuki N, Mittler R (2012) Reactive oxygen species-dependent wound responses in animals and plants. Free Radic Biol Med 53:2269-2276

76. Tang C, Shen C, Zhu KY, Zhou YX, Chuang YJ, He CY, Zuo ZH (2020) Exposure to the AhR agonist cyprodinil impacts the cardiac development and function of zebrafish larvae. Ecotox Environ Safe 201:110808 
77. Teraoka H, Dong W, Tsujimoto Y, Iwasa H, Endoh D, Ueno N, Stegeman JJ, Peterson RE, Hiraga T (2003) Induction of cytochrome P450 1A is required for circulation failure and edema by 2,3,7,8tetrachlorodibenzo-p-dioxin in zebrafish. Biochem Biophys Res Commun 304(2):223-228

78. Thais SS, María FG, Carmen GB, Jesús SG, Beatriz CG, Raquel RO (2019) Impact of mepanipyrim and tetraconazole in Mencía wines on the biosynthesis of volatile compounds during the winemaking process. Food Chem 300:125223

79. Velki M, Meyer-Alert H, Seiler TB, Hollert H (2017) Enzymatic activity and gene expression changes in zebrafish embryos and larvae exposed to pesticides diazinon diuron. Aquat Toxicol 193:187-200

80. Voelker D, Stetefeld N, Schirmer K, Scholz S (2008) The role of cyp1a and heme oxygenase 1 gene expression for the toxicity of 3,4-dichloroaniline in zebrafish (Danio rerio) embryos. Aquat Toxicol 86(1):112-120

81. Vogel CFA, Van Winkle LS, Esser C, Haarmann-Stemmann T (2020) The aryl hydrocarbon receptor as a target of environmental stressors: Implications for pollution mediated stress and inflammatory response. Redox Biol 34:101530

82. Wang WD, Chen GT, Hsu HJ, Wu CY (2015) Aryl hydrocarbon receptor 2 mediates the toxicity of Paclobutrazol on the digestive system of zebrafish embryos. Aquat Toxicol 159:13-22

83. Whyte JJ, Jung RE, Schmitt CJ, Tillitt DE (2000) Ethoxyresorufin-O-deethylase (EROD) activity in fish as a biomarker of chemical exposure. Crit Rev Toxicol 30:347-570

84. Xie SL, Junaid M, Bian WP, Luo JJ, Syed JH, Wang C, Xiong WX, Ma YB, Niu A, Yang XJ, Zou JX, Pei DS (2018) Generation and application of a novel transgenic zebrafish line $T g$ (cyp1a:mCherry) as an in vivo assay to sensitively monitor PAHs and TCDD in the environment. J Hazard Mater 344:723732

85. Xu HY, Li CX, Suklai P, Zeng QH, Chong R, Gong ZY (2018) Differential sensitivities to dioxin-like compounds PCB126 and PeCDF between $T g(c y p 1 a: g f p)$ transgenic medaka and zebrafish larvae. Chemosphere 192:24-30

86. Zangar RC, Davydov DR, Verma S (2004) Mechanisms that regulate production of reactive oxygen species by cytochrome P450. Toxicol Appl Pharmacol 199:316-331

87. Zhang Q, Ji C, Yan L, Lu M, Lu C, Zhao M (2016) The identification of the metabolites of chlorothalonil in zebrafish (Danio rerio) and their embryo toxicity and endocrine effects at environmentally relevant levels. Environ Pollut 218:8-15

88. Zhao Q, Shi F, Zhu L (2017) Prometryn and humic acid induce Cytochrome P450 1A expression in Danio rerio (zebrafish). Ecotox Environ Safe 135:40-47

89. Zhou YX, Shen C, Du H, Bao YY, He CY, Wang CG, Zuo ZH (2019) Bioassay system for the detection of aryl hydrocarbon receptor agonists in waterborne pesticides using zebrafish cyp 1a 1 promoterluciferase recombinant hepatic cells. Chemosphere 220, 61-68

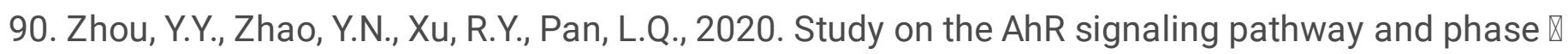
detoxification metabolic enzymes isoforms in scallop Chlamys farreri exposed to single and mixtures of PAHs. Environ. Res. 190, 109980. 
91. Zhu KY, Shen C, Tang C, Zhou YX, He CY, Zuo ZH (2021) Improvement in the screening performance of potential aryl hydrocarbon receptor ligands by using supervised machine learning. Chemosphere 265:129099

92. Zodrow JM, Stegeman JJ, Tanguay RL (2004) Histological analysis of acute toxicity of 2,3,7,8tetrachlorodibenzo-p-dioxin (TCDD) in zebrafish. Aquat Toxicol 66(1):25-38

\section{Tables}

Due to technical limitations, Table 3 is only available as a download in the Supplemental Files section.

\section{Figures}
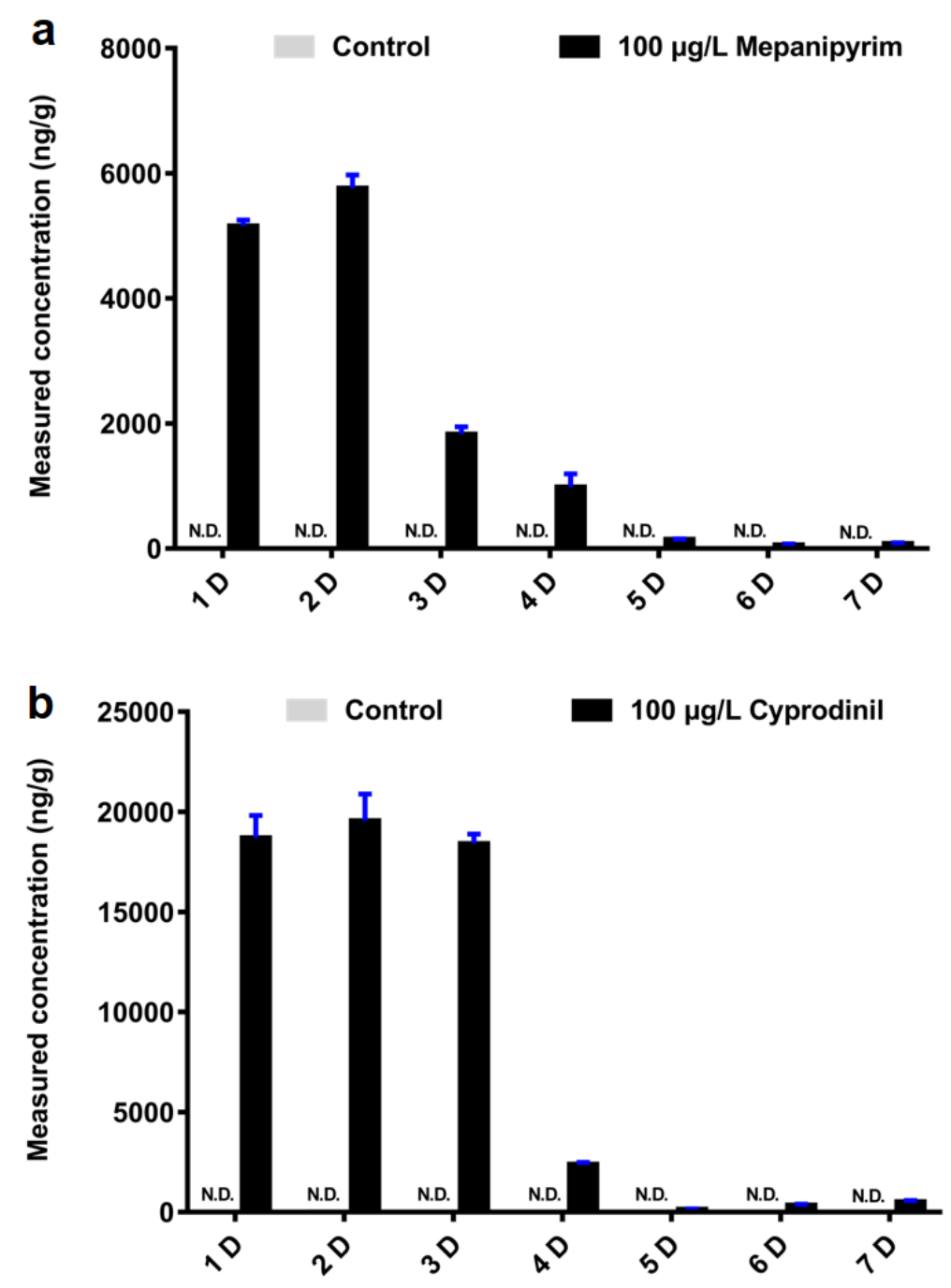

\section{Figure 1}

Measured concentrations of mepanipyrim (a) and cyprodinil (b) ( $\mathrm{ng} / \mathrm{g} \pm \mathrm{SD})$ in zebrafish larvae or embryos $(n=3)$. Zebrafish embryonic exposure to $100 \mu \mathrm{g} / \mathrm{L}$ mepanipyrim or cyprodinil for $1,2,3,4,5,6$, 
and 7 days (D), the residues of mepanipyrim or cyprodinil in different developmental stages of zebrafish were detected. N.D. represents no detection.
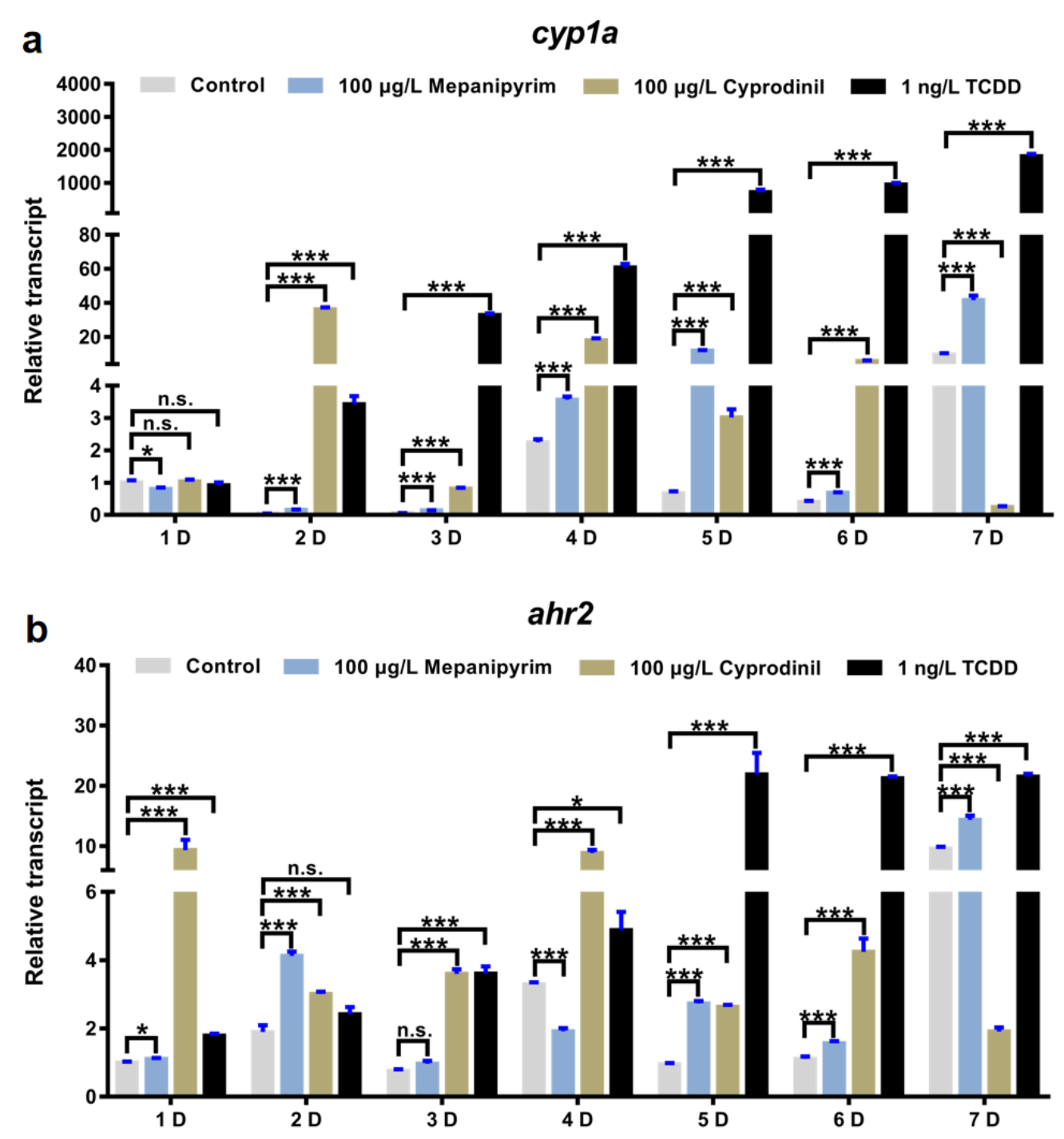

Figure 2

The mRNA expression of cyp1a and ahr2 genes in zebrafish embryos and larvae. The expression of cyp1a (a) and ahr2 (b) exhibited dynamic change by $100 \mu \mathrm{g} / \mathrm{L}$ mepanipyrim or cyprodinil exposure, and strongly inducted by $1 \mathrm{ng} / \mathrm{L} \mathrm{TCDD}$ exposure. The data (mean \pm standard errors, $n=6$ ) were analysed using the Duncan's post hoc test after one-way analysis of variance (ANOVA). ${ }^{*} * \mathrm{P}<0.001 ; * 0.01<\mathrm{P}<$ 0.05 ; n.s. indicates no significant difference. D: days. 


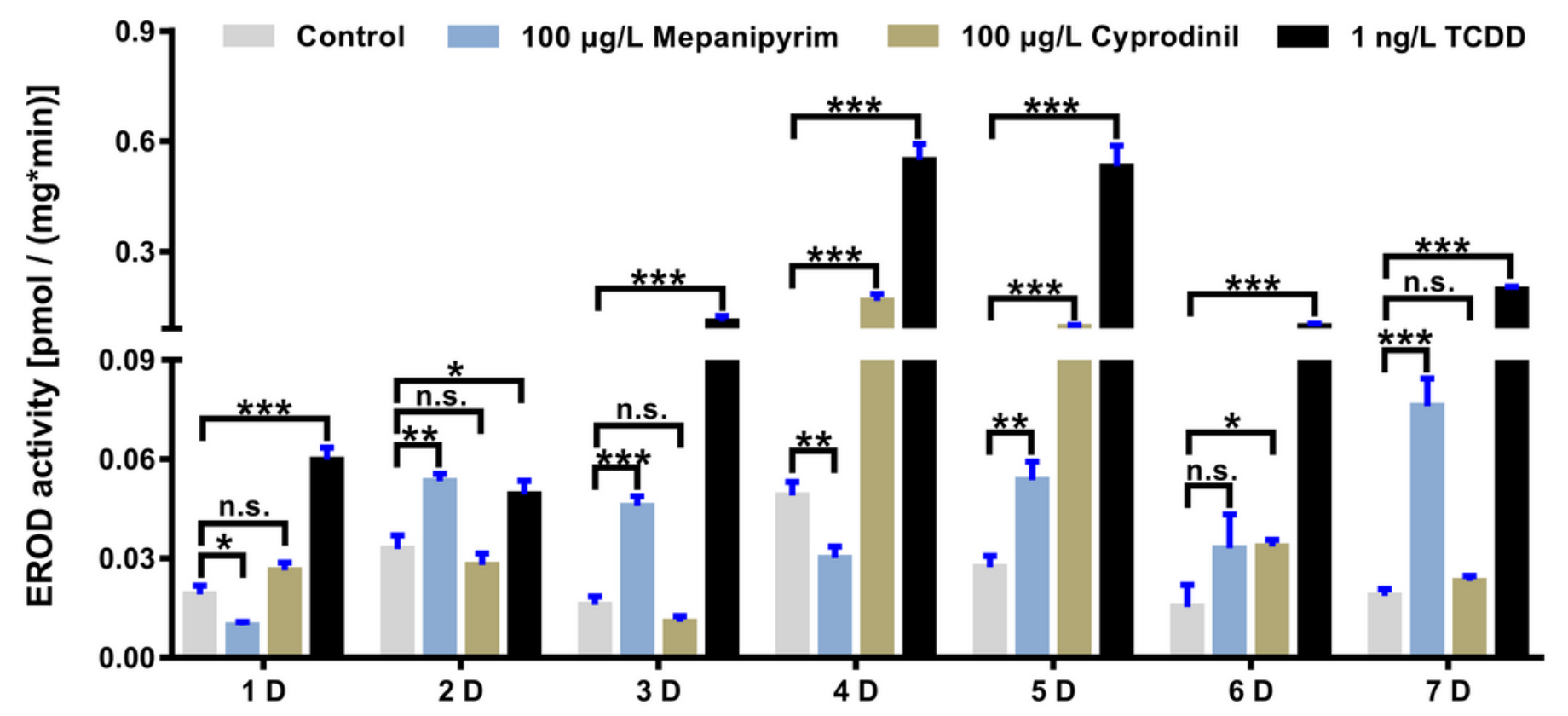

Figure 3

Detection of EROD activity in zebrafish embryos and larvae. EROD activity of embryos or larvae exhibited dynamic change by $100 \mu \mathrm{g} / \mathrm{L}$ mepanipyrim or cyprodinil exposure, and strongly increased by $1 \mathrm{ng} / \mathrm{L}$ TCDD exposure. The data (mean \pm standard errors, $n=6$ ) were analysed using the Duncan's post hoc test after one-way analysis of variance (ANOVA). ${ }^{* \star *}<<0.001 ; * * 0.001<P<0.01 ; * 0.01<P<0.05 ;$ n.s. indicates no significant difference. D: days.

\section{Supplementary Files}

This is a list of supplementary files associated with this preprint. Click to download.

- 20210803Supplementarymaterials.doc 